\title{
Effects of Two Modes of Computer Assisted Instruction on Pupils' Achievement and Retention in English Language Spelling in Niger State- Nigeria
}

\author{
Dr. Aniah Anthony, Sani Shahid Anka
}

\begin{abstract}
The study investigated the effects of two modes of Computer Assisted Tutorial, Drill and Practice Instructional packages (CAI) on Pupils Achievement and Retention in English Language Spelling in Niger State. Findings show that CAI Tutorial, drill and practice packages mode strategy of instruction enhanced achievement and retention of English language spelling. The study adopted quasi-experimental design. Purposive sampling was used to select six schools from the seven educational zones in Niger State. The study sample comprised of 87 males and 93 females. Experimental groups were taught with CAI Tutorial, Drill and Practice packages while Control group was taught with lecture method. Six research questions and six hypotheses guided the study. English Language Achievement Test (ELAT) was used for data collection. The CAI packages and ELAT were face validated by experts while the reliability was established using Kuder Richardson (KR 20) analysis and the reliability coefficient was found to $b e r=0.74$. Mean and standard deviation were used to analyze the research questions while analysis of covariance (ANCOVA) was used in the testing of the hypotheses. It is recommended that, curriculum planners should infuse CAI packages into English language programmes so that primary school teachers' can use it to teach English language concepts.
\end{abstract}

KEYWORDS- Achievement, CAI modes, Effects, English Language Spelling, Retention.

Manuscript received May 20, 2020

Aniah Anthony, Senior Lecturer, Department of Educational Technology, Federal University of Technology, Minna Niger State, Nigeria. (e-mail: anthonyaniah@futminna.edu.ng )

Sani Shahid Anka, Principal Instructor 1, Department of Office Technology and Management, Abdu Gusau Polytechnic, Talata Mafara, Zamfara State, Nigeria.

\section{INTRODUCTION}

The role English language plays in the world of communication and scientific advancement cannot be over emphasized. English Language is Nigeria's lingua franca and the medium of instruction in the educational institutions from the primary schools to tertiary institutions. The government of Nigeria considers English language as a core subject in the school curriculum and a major medium of communication both within and outside the school system. The aims of teaching the English language especially at the primary school level of education is to understand the four language skills of listening, speaking, reading and writing. The poor performance in English language at all levels of education especially at the primary school level leaves much to be desired. Nigeria as a developing nation requires solid foundation in its education system at the primary school level if it must compete favorably with other nations of the world. In this study, the researcher's developed computer assisted tutorial, drill and practice instructional packages will be used to teach English language spellings using alphabets A-J in primary two with a view to determine their effects on pupil' achievement in Niger State.

\section{A. Related Works}

The National Policy on Education demands the ability to communicate effectively in English language at the primary school being the foundation of all levels of education [1]. [2] Stated that the problem of poor level of achievement of primary school children is a serious one in Nigeria. [3] also confirmed that the performance of the primary school pupils in English language was very poor. He explained that the poor standard was due to a number of reasons such as: the use of tribal language in the lower classes of primary school, some pupils do not understand the grammar because their teachers themselves do not know it and in most cases English language teachers in the senior primary schools resort to the use of mother tongue to explain the English language even up to the secondary school level [3]. According to [4] the non - availability of teaching materials is one of the factors which contribute to poor teaching by teachers and the consistent failure in English language examinations. Other factors that have 
been identified as responsible for the poor achievement in English language include non-utilization of audio-visual instructional materials, poor English language teaching and expression, poor knowledge of the subject by the teacher and lack of textbooks among others. Based on the above fact, it has become imperative for Nigeria and indeed Niger State to integrate and use CAI in teaching English language spelling in primary schools to enhance students' achievement and retention [5]. Spelling can be defined as an act of forming words correctly using letters of alphabets. National Teachers Institute, Manual for Retraining of Primary School Teachers [6] stated that spelling involves associating letters with certain sounds or words. According to Tompkins [7] spelling is a developmental process. [8] Explained that learning to spell is a multisensory process hence students use their eyes, ears, hands stressing that students will have difficulty with spelling when they rely on one type of sense. The major purpose of learning spelling is for effective communication both oral and in written form. To facilitate pupils learning of spelling, the teacher provides range of activities such as:

Use of Computer: Many students find using a computer motivating in improving their spelling. Computers have the ability to locate words with their spelling. [9] Believed that students with learning difficulties can develop positive attitude towards drill and practice using spelling programs on computer. Pupils' activity on computer could require them to type words on the computer and check spellings, word search, typing of words in alphabetical order, match letters with pictures or words.

Texting: This has attracted concerns that text messages could be contributing to poor spelling. However, [10] and [11] in their research on English language spelling programs indicate that texting using phones does not have negative impact on student's spelling. The authors explained that rather than being a negative influence, texting allows texters to practice and experience success in reading and speaking on a daily basis stressing that texting is dependent on initial letters and abbreviations. It builds sound-letters relationship which contribute to successful reading and spelling development. A tutorial is a method of transferring knowledge and may be used as part of a learning process. A tutorial seek to teach by example and supply the information to complete a certain task. A tutorial can take one of many forms, ranging from a set of instructions to complete a task to an interactive problem solving session usually in academic [12]. In computer based education, a tutorial is a computer program whose purpose it is to assist users in learning how to use parts of a software product such as an office suite or any other application, operating system interface, programming tool, or video game. There are three kinds of software tutorials: video tutorial; is that which the user views, interactive tutorials where the user follows on-screen instructions, whereupon he/she does the tutorial exercises and receive feedback depending on his/her action; and webinars where users participate in real-time lectures, online tutoring, or workshops remotely using web conferencing software. [13] Describe tutorial as a system that presents initial learning task to the pupils as opposed to the drill and practice mode characterized by the presentation of a set of questions and their corresponding answers. The characteristics of the tutorial program are text presentation in small step; actual learners participation in the learning process, frequent feedback and reinforcement. The tutorial mode is used in teaching school subjects, like language words and spelling; mathematics, social studies, primary science and French. A tutorial provides pupils with series of lessons. The lessons are designed to help the pupils learn how to use the specific program. The pupils can select a lesson from a "menu". The menu is displayed on a monitor. The lesson guides the pupil through a series of "displays" or "screens". Drill and practice is an educational strategy that promotes the acquisition of knowledge skill through repetitive practice. Drill and practice involves the use of specific skills such as addition and subtraction or spelling. Its' main purpose is to help learners master materials at their own pace. Drills are used as reinforcement tool and is mainly for the beginning learner or for students who are experiencing learning problems. Drill and practice software packages provides feedback to students, explain how to get correct answer and contain a management system to keep track of student progress. Drill and practice exercises with the appropriate software can enhance the daily classroom experience. The procedure for using CAI tutorial, drill and practice in instructional delivery are the same, for instance, in teaching letters A-J, only one letter at a time is treated. If a child gets an option or answer correct after the teaching, the teacher proceed to the next letter but if the child gets the option wrong, revisit the same letter until the child gets it right. This procedure is applicable to all the letters A-J. However, the major difference between the two modes is that in drill and practice, there is practice and repetition while tutorial software present concepts or skills and then give students opportunity to practice to enhance achievement. Achievement is the extent to which a student, teacher or institution achieved their short or long term goals. Academic achievement is commonly measured through examinations or continuous assessment. However, there are inconclusive results over which individual factors successfully predict academic achievement, hence, elements such as test anxiety, environment, motivation and emotion requires consideration when developing models for school achievement [14] Relating this to academic achievement in this context means success in English language spelling when computer assisted tutorial, drill and practice instructional packages are used as medium of instruction for ease of retention of material learnt. [15] Stated that retention involves the ability to recall the content that has been given within a specific period of time. The authors explained that it is the ability to demonstrate what the learner has learnt and being able to demonstrate his/her cognitive skills in the subject. However, pupils' ability to reproduce the learnt material could be through the use of an appropriate instructional material like computer assisted instructional packages in teaching. Learning could be made more effective, lasting and enjoyable and topics that are abstract to students could be made clearer, easier 
and meaningful for better achievement of concept learnt. CAI packages could also reduce the perceived stereotyped status of pupils' in the learning of English language in the sense that every pupils in the study will have access to the packages and also learn them at his or her convenient time and pace. Gender difference is also one of the factors affecting learning, studies on the influence of gender on achievement have not produced conclusive results. Some findings indicated that significant differences existed between the performance of male and female students while other findings showed that gender factor had no influence on students' performance [16]. This contractive evidence in academic achievement due to gender had resulted in the need to verify how computer assisted instructional packages can influence pupils' achievement in English language spelling.

\section{B. Statement of the Research Problem}

The achievement of pupils in English language has not been encouraging despite its importance to national development. The researchers observed that pupils have serious difficulties in comprehension of English language (spelling) because of non-utilization of instructional materials, poor knowledge of the subject and expression by the teachers, lack of relevant textbooks that contains dictation or spelling activities. Furthermore, the poor retention in English could also be attributed to the teacher's teaching methods and non-usage of modern instructional facilities like computer and other internet connectivity. This has contributed to poor performance of pupils at the primary school level. This poor performance gives all those interested in the standard of education cause for concern and calls for urgent action to reverse the situation from primary school which is the foundation for other levels of education. Thus, to enhance the teaching of spelling, the pupils must first know their alphabets and should be able to listen to people to inculcate in them the skill of listening. It is against this background that the study investigated the effects of computer assisted tutorial, drill and practice instructional packages on achievement and retention of pupils' in English language spelling in Niger State.

\section{a. Objective of the Study}

The objective of this study was to find out the effects of computer assisted instructional packages on Pupils' Achievement and Retention on Spelling in English Language in Niger State. Specifically, the study has the following objectives:

1. Determine the effect of CAI tutorial, CAI drill and practice package on the mean achievement scores of pupils' taught English Language Spelling.

2. Determine the effect of CAI tutorial, CAI drill and practice package on the mean retention scores of pupils' taught English Language Spelling.

3. Determine the effect of CAI tutorial package on the mean achievement scores of male and female pupils' taught English Language Spelling.
4. Determine the effect of CAI drill and practice package on the mean achievement scores of male and female pupils' taught English Language Spelling.

5. Determine the effect of CAI tutorial package on the mean retention scores of male and female pupils taught English Language Spelling.

6. Determine the effect of CAI drill and practice on the mean retention scores of male and female pupils taught English Language Spelling.

\section{b. Scope of the Study}

The scope of this study is the effects of two modes of computer assisted instructional package on pupils' achievement and retention on spelling of English language in Niger State. Primary two was used in the study and the topic that was covered is spellings using ten English language alphabets A-J. The topics were presented using CAI tutorial, CAI drill and practice mode of instruction. Time frame was four weeks.

\section{c. Research Questions}

The following research questions guided this study.

1. What are the mean achievement scores of pupils taught English Language Spelling with CAI Tutorial, CAI Drill and Practice and lecture method?

2. What are the mean retention scores of pupils taught English Language Spelling with CAI Tutorial, CAI Drill and Practice and lecture method?

3. What are the mean achievement scores of male and female pupils taught English language spelling with CAI tutorial package?

4. What are the mean achievement scores of male and female pupils taught English language spelling with CAI drill and practice?

5. What are the mean retention scores of male and female pupils taught English language spelling with CAI tutorial package?

6. What are the mean retention scores of male and female pupils taught English language spelling with CAI drill and practice?

\section{d. Research Hypotheses}

The following null hypotheses were formulated and tested at 0.05 Alpha Level of significance.

$\mathbf{H O}_{1}$ : There is no significant difference in the mean achievement scores of pupils taught English Language Spelling with CAI Tutorial, CAI Drill and Practice and lecture method.

$\mathbf{H O}_{2}$ : There is no significant difference in the mean retention scores of pupils taught English Language Spelling with CAI Tutorial, CAI Drill and Practice and lecture method.

$\mathbf{H O}_{3}$ : There is no significant difference in the mean achievement scores of male and female pupils taught English language spelling with CAI tutorial package.

$\mathbf{H O}_{4}$ : There is no significant difference in the mean achievement scores of male and female pupils taught English language spelling with CAI drill and practice. 
HO $\mathbf{5}_{5}$ : There is no significant difference in the mean retention scores of male and female pupils taught English language spelling with CAI tutorial package.

HO : There is no significant difference in the mean retention scores of male and female pupils taught English language spelling with CAI drill and practice.

\section{METHODOLOGY}

The study adopted quasi- experimental design. Specifically, a pretest posttest non- equivalent control group design was used. This is because intact classes (i.e pre-existing groups) were used, since randomization was not possible. The research design layout is as follows:

$\begin{array}{llll}\begin{array}{l}\text { Groups } \\ \begin{array}{l}\text { Experimental } \\ \text { Group 1 }\end{array}\end{array} & 01 & \begin{array}{l}\text { Pretest } \\ \text { (CAI Tutorial)X1 }\end{array} & \begin{array}{l}\text { Posttest } \\ 02\end{array} \\ \begin{array}{l}\text { Experimental } \\ \text { Group 2 }\end{array} & 01 & \begin{array}{l}\text { (CAI Drill and } \\ \text { Practice)X2 }\end{array} & 02 \\ \text { (CLM) X3 } & 02\end{array}$

$\begin{array}{lll}01 & \mathrm{x} 1 & 02\end{array}$

$\begin{array}{lll}01 & \mathrm{x} 2 & 02\end{array}$

$\begin{array}{lll}01 & \mathrm{x} 3 & 02\end{array}$

01 - represents pretest observation on English Language spelling and Achievement test of experimental group 1,2 and control group.

02 - represents posttest observation on English Language spelling and Achievement test of the experimental group 1, 2 and control group.

X1 - represents treatment for experimental group.1

X2 - represents treatment for experimental group 2

X3 - represents control group without treatment.

\section{A. Area of the Study}

The study was carried out in Niger State because the state is one of the states that primary school pupils have been identified with the problem of poor performance in English language and that no serious effort made to address the situation. The state has seven educational zones.

\section{a. Population of the Study}

The population of the study comprises all the public primary schools in the seven educational zones in Niger State. The number of public primary schools in the seven education zones is 2,603 . The population of pupils in these schools is $135,245$.

\section{b. Sample and Sampling Techniques}

Multistage sampling technique was employed, purposive random sampling technique was adopted to obtain the six selected public primary schools in the three senatorial zones comprising of seven educational zones in Niger State. The six selected public primary schools were randomly assigned to the two experimental and control group. Two schools were each assigned to experimental and control group. One intact class was assigned to each experimental and control group school. The experimental groups comprised of 53 males and 67 female making a total of 120 pupils while the control group comprised of 34 males and 26 females.

\section{c. Instrument for Data Collection}

The instrument that was used in collecting data for this study is the researcher made English language Achievement Test on Spelling (ELAT). The English Language Achievement Test covered spellings using ten English language alphabets A-J. The chosen concepts were selected from primary two pupils English language syllabus and it corresponds to what the pupils should be taught in their school at the time of study.

\section{d. Validation of Research Instruments}

Four Educational Technology experts from Federal University of Technology Minna validated the packages in terms of the appropriateness of the packages for the chosen topics, clarity and simplicity as well as its suitability for the level of the pupils. The experts comment, suggestions and recommendations were used to improve on the packages.

The English language content of the packages were also validated by four experts, two from school of General Studies, Federal University of Technology, Minna and the other two from the Department of English language, College of Education Minna. The experts assessed the face and content validity of the instrument in relation to primary two pupils' curriculum. The experts examined the instruments in terms of Clarity of spellings, words formed at the pupils level of understanding and agreement of words formed with the test blue print. The test items and contents of the packages were later modified on the basis of suggestions and recommendation of experts.

\section{e. Reliability of Instrument}

The reliability of the instrument was obtained using a sample size of 30 primary two pupils' who constitute part of the population but were not used in the main study. This 30 pupils were subjected to a test-retest method of reliability at an interval of two weeks. Hence, two set of scores were obtained and subjected to Pearson Product Moment Correlation Co-efficient formula (PPMC). A correlation coefficient of $\mathrm{r}=0.74$ was obtained from the analysis. This value therefore revealed that the instrument was reliable.

\section{f. Method of Data Collection}

The instrument that was used for data collection in this study was (ELAT) administered to the pupils as experimental treatment. The scores obtained from both the experimental and control group served as posttest scores in the study, the scores was used to determine the academic achievement and retention of both groups. The scores of the experimental and control group on the posttest were computed, recorded and use for data analyses.

\section{g. Method of Data Analysis}

The research questions were answered using mean and standard deviation. The hypotheses were analyzed using analysis of covariance (ANCOVA) using statistical package for social sciences (SPSS). Analysis of covariance are used when treatment is given as pretest and posttest and 
differences compared. The significance of the various statistical analyses were ascertained at 0.05 alpha levels.

\section{h. Results}

The result was presented in line with the research questions and hypotheses that guided the study.
Research Question 1: What are the mean achievement scores of pupils taught English Language Spelling with CAI Tutorial, CAI Drill and Practice and Lecture method using alphabet A-J?

Table 1: Mean Achievement Scores of Pupils taught English Language Spelling with CAI Tutorial, CAI Drill and Practice and Lecture Method using alphabet A-J.

\begin{tabular}{|c|c|c|c|c|c|c|}
\hline Group & $\mathbf{N}$ & Prete & & Postte & & Mean Gain \\
\hline & & Mean & SD & Mean & SD & \\
\hline Expt.1 (CAI Tutorial) & 60 & 17.17 & 6.47 & 57.70 & 3.08 & 40.53 \\
\hline $\begin{array}{llll}\text { Expt. 2 } & \text { (CAI Drill and } \\
\text { Practice) } & & & \end{array}$ & 60 & 19.97 & 3.03 & 54.20 & 7.36 & 34.23 \\
\hline Control (Lecture Method) & 60 & 19.37 & 3.26 & 38.53 & 2.87 & 19.16 \\
\hline Total & 180 & 18.83 & 4.66 & 50.14 & 9.67 & 31.31 \\
\hline
\end{tabular}

Table 1 shows a pretest mean achievement scores of 17.17 and standard deviation of 6.47 for experimental group 1, a pretest mean achievement score of 19.97 and standard deviation of 3.03 for the experimental group 2, and a pretest mean achievement score of 19.37 and standard deviation of 3.26 for the control group. The total means of 18.83 and SD of 4.66 show that the three groups were originally at an equivalent level of achievement. For the posttest, the experimental group 1 obtained higher mean achievement score of 57.70 with a standard deviation of 3.08. The experimental group 2 obtained a mean of 54.20 with SD of 7.36 while the control group obtained a mean achievement score of 38.53 with a standard deviation of 2.87 . The total posttest mean and standard deviation scores for the three groups were 50.14 and 9.67. The mean gain scores for the three groups were 40.53 (experimental 1), 34.23(experimental 2) and 19.16 for control group. Hence, CAI tutorial package and CAI drill and practice enhanced pupils' achievement in English Language Spelling using alphabet A-J.

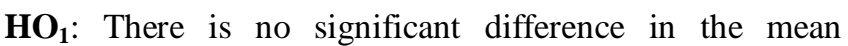
achievement scores of pupils taught English Language Spelling with CAI Tutorial, CAI Drill and Practice and lecture method using alphabet A-J.

Table 2: Summary of ANCOVA for Achievement Scores of Pupils taught English Language Spelling with CAI Tutorial, CAI Drill and Practice and Lecture Method using alphabet A-J.

\begin{tabular}{|l|l|l|l|l|l|l|}
\hline Source & $\begin{array}{l}\text { Type III Sum of } \\
\text { Squares }\end{array}$ & Df & Mean Square & F & Sig. & Decision \\
\hline Corrected Model & $12585.462(a)$ & 3 & 4195.154 & 177.539 & .000 & \\
\hline Intercept & 21665.976 & 1 & 21665.976 & 916.906 & .000 & \\
\hline Pretest & 84.351 & 1 & 84.351 & 3.570 & .060 & \\
\hline Method & $\mathbf{1 2 5 6 2 . 7 1 3}$ & $\mathbf{2}$ & $\mathbf{6 2 8 1 . 3 5 7}$ & $\mathbf{2 6 5 . 8 2 7}$ & $\mathbf{. 0 0 0}$ & S \\
\hline Error & 4158.783 & 176 & 23.629 & & & \\
\hline Total & 469348.000 & 180 & & & & \\
\hline Corrected Total & 16744.244 & 179 & & & & \\
\hline
\end{tabular}

Significant $(\mathrm{p}<0.05)$

Table 2 shows the F value $\mathbf{( 2 6 5 . 8 2 7 )}$ with $\mathrm{df}(2,176)$ and $\mathrm{p}$ value of $\mathbf{. 0 0 0}$. Since this value is less than 0.05 level of significance. Hence, H01 was rejected. Therefore, there was significant difference in the mean achievement scores of pupils taught English Language Spelling with CAI Tutorial, CAI Drill and Practice and lecture method using alphabet A-J. This shows that CAI Tutorial, CAI Drill and Practice did improve pupils' achievement in English Language
Spelling. [17] Findings on effect of CAI language learning in teaching grammar support the present study which showed that the instructional method CAI was in favour of the experimental group.

Research Question 2: What are the mean retention scores of pupils taught English Language Spelling with CAI Tutorial, CAI Drill and Practice and Lecture method using alphabet A-J? 
Table 3: Mean Retention Scores of Pupils taught English Language Spelling with CAI Tutorial, CAI Drill and Practice and Lecture Method using alphabet A-J.

\begin{tabular}{|l|l|lc|}
\hline Group & N & Mean & SD \\
\hline Expt.1 (CAI Tutorial) & 60 & 57.80 & 4.08 \\
\hline Expt. 2 (CAI Drill and Practice) & 60 & 54.93 & 5.41 \\
\hline Control (Lecture Method) & 60 & 38.93 & 4.22 \\
\hline Total & $\mathbf{1 8 0}$ & $\mathbf{5 0 . 5 6}$ & $\mathbf{9 . 5 0}$ \\
\hline
\end{tabular}

Table 3 shows the English Language spelling mean retention scores of Experimental 1 (CAI Tutorial), Mean 57.80 with SD 4.08, Experimental 2 (CAI Drill and Practice) Mean 54.93 with SD 5.41and Control (Lecture Method) Mean 38.93, SD 4.22 respectively. This shows that Experimental 1 (CAI Tutorial) enhanced pupils' retention in spelling most, followed by Experimental 2 (CAI Drill and Practice).

$\mathbf{H O}_{2}$ : There is no significant difference in the mean retention scores of pupils taught English Language Spelling with CAI Tutorial, CAI Drill and Practice and lecture method using alphabet A-J.

Table 4: Summary of ANCOVA for Retention Scores of Pupils taught English Language Spelling with CAI Tutorial, CAI Drill and Practice and Lecture Method using alphabet A-J.

\begin{tabular}{|l|l|l|l|l|l|l|}
\hline Source & $\begin{array}{l}\text { Type III Sum of } \\
\text { Squares }\end{array}$ & Df & Mean Square & F & Sig. & Decision \\
\hline Corrected Model & 12464.037 & 3 & 4154.679 & 197.393 & .000 & \\
\hline Intercept & 3319.547 & 1 & 3319.547 & 157.715 & .000 & \\
\hline Posttest & 60.660 & 1 & 60.660 & 2.882 & .091 & \\
\hline Method & $\mathbf{2 4 4 3 . 0 0 6}$ & $\mathbf{2}$ & $\mathbf{1 2 2 1 . 5 0 3}$ & $\mathbf{5 8 . 0 3 5}$ & $\mathbf{. 0 0 0}$ & S \\
\hline Error & 3704.407 & 176 & 21.048 & & & \\
\hline Total & 476224.000 & 180 & & & & \\
\hline Corrected Total & 16168.444 & 179 & & & & \\
\hline
\end{tabular}

Significant $(\mathrm{p}<0.05)$

Table 4 shows $F(58.035)$ with $\mathrm{df}(2,176)$ and $\mathrm{P}$-value of 0.000. Since P-value is less than 0.05. Hence, H02 was rejected. Therefore, there was significant difference in the mean retention scores of pupils taught English Language Spelling with CAI Tutorial, CAI Drill and Practice and lecture method using alphabet A-J. [17] Findings on effect of CAI language learning in teaching grammar support the present study which showed that the instructional method CAI was in favour of the experimental group. This result agrees with [18] who reported that children exposed to computer have positive attitude towards learning than those not exposed to the same treatment. The study carried out by [19] on use of CAI drill and practice on hearing impaired pupils agree with [18] that the use of CAI enhanced learner's retention stressing that their satisfaction level was good.

Research Question 3: What are the mean achievement scores of male and female pupils taught English language spelling using alphabet A-J with CAI tutorial package?

Table 5: Mean Achievement Scores of Male and Female Pupils taught English Language Spelling using alphabet A-J with CAI Tutorial Package.

\begin{tabular}{|l|l|l|l|l|l|l|}
\hline & \multicolumn{3}{|l|}{ Pretest } & \multicolumn{2}{l|}{ Posttest } & \\
\hline $\begin{array}{l}\text { Expt. 1 (CAI tutorial package) } \\
\text { Gender }\end{array}$ & $\mathbf{N}$ & Mean & SD & Mean & SD & $\begin{array}{l}\text { Mean } \\
\text { Gain }\end{array}$ \\
\hline Male & 25 & 17.52 & 6.25 & 57.04 & 3.88 & $\mathbf{3 9 . 5 2}$ \\
\hline Female & 35 & 16.91 & 6.69 & 58.17 & 2.63 & $\mathbf{4 1 . 2 6}$ \\
\hline Total & 60 & 17.17 & 6.47 & 57.70 & 3.23 & $\mathbf{4 0 . 3 9}$ \\
\hline
\end{tabular}


Table 5 shows that the mean achievement scores of male and female pupils taught English language spelling using alphabet A-J with CAI tutorial package. Male Mean Scores 57.04, SD 3.88 and Female Mean Scores 58.17, SD 2.63 respectively. The mean achievement score of female pupils is higher than that of their male counterparts. The mean gain of male pupils is 39.52 while that of female is 41.26 . This suggests that both female and male pupils achieved almost equally when taught English language spelling using alphabet A-J with CAI tutorial package.

$\mathbf{H O}_{3}$ : There is no significant difference in the mean achievement scores of male and female pupils taught English language spelling using alphabet A-J with CAI tutorial package.

Table 6: Summary of ANCOVA for Achievement Scores of Male and Female Pupils taught English Language Spelling using alphabet A-J with CAI Tutorial Package.

\begin{tabular}{|l|l|l|l|l|l|l|}
\hline Source & $\begin{array}{l}\text { Type III Sum of } \\
\text { Squares }\end{array}$ & Df & Mean Square & F & Sig. & Decision \\
\hline Corrected Model & 63.186 & 2 & 31.593 & 3.266 & .045 & \\
\hline Intercept & 22217.356 & 1 & 22217.356 & 2296.623 & .000 & \\
\hline Pretest & 44.518 & 1 & 44.518 & 4.602 & .036 & \\
\hline Gender & $\mathbf{2 1 . 4 0 7}$ & $\mathbf{1}$ & $\mathbf{2 1 . 4 0 7}$ & $\mathbf{2 . 2 1 3}$ & $\mathbf{. 1 4 2}$ & NS \\
\hline Error & 551.414 & 57 & 9.674 & & & \\
\hline Total & 200372.000 & 60 & & & & \\
\hline Corrected Total & 614.600 & 59 & & & & \\
\hline
\end{tabular}

Not Significant $(\mathrm{p}>0.05)$

Table 6 shows that $F$ value (2.213) has a probability value of .142. Since $P$ value is greater than 0.05 level of significance, the null hypothesis was retained. Therefore, there was no significant difference in the mean achievement scores of male and female pupils taught English language spelling using alphabet A-J with CAI tutorial package. This result is supported by [16] who stated that gender has no impact on learning. In the same light, [20] posit that computer is gender friendly. This shows that CAI tutorial package is not gender biased in teaching English language spelling using alphabet A-J.

Research Question 4: What are the mean achievement scores of male and female pupils taught English language spelling using alphabet A-J with CAI drill and practice?

Table 7: Mean Achievement Scores of Male and Female Pupils taught English Language Spelling using alphabet A-J with CAI Drill and Practice.

\begin{tabular}{|l|l|l|l|l|l|l|}
\hline & \multicolumn{3}{l|}{ Pretest } & \multicolumn{2}{l|}{ Posttest } & \\
\hline $\begin{array}{l}\text { Expt. 2 (CAI Drill and Practice) } \\
\text { Gender }\end{array}$ & N & Mean & SD & Mean & SD & $\begin{array}{l}\text { Mean } \\
\text { Gain }\end{array}$ \\
\hline Male & 28 & 19.00 & 3.01 & 55.00 & 7.92 & $\mathbf{3 6 . 0 0}$ \\
\hline Female & 32 & 20.81 & 2.82 & 54.56 & 6.47 & $\mathbf{3 3 . 7 5}$ \\
\hline Total & 60 & 19.97 & 3.03 & 54.77 & 7.12 & $\mathbf{3 4 . 8 8}$ \\
\hline
\end{tabular}

Table 7 shows the mean achievement scores of male and female pupils taught English language spelling using alphabet A-J with CAI drill and practice package. Male mean score 55.00, SD 7.92 and Female mean score 54.56, SD 6.47respectively. The mean achievement score of male pupils is higher than that of the female. The mean gain of male pupils is 36.00 while that of their female counterparts is 33.75. This suggests that both female and male pupils achieved almost equally when taught English language spelling using alphabet A-J with CAI drill and practice.

$\mathbf{H O}_{4}$ : There is no significant difference in the mean achievement scores of male and female pupils taught English language spelling using alphabet A-J with CAI drill and practice 
Effects of Two Modes of Computer Assisted Instruction on Pupils' Achievement and Retention in English Language Spelling in Niger State-Nigeria

Table 8: Summary of ANCOVA for Achievement Scores of Male and Female Pupils taught English Language Spelling using alphabet A-J with CAI Drill and Practice

\begin{tabular}{|l|l|l|l|l|l|l|}
\hline Source & $\begin{array}{l}\text { Type III Sum of } \\
\text { Squares }\end{array}$ & Df & Mean Square & F & Sig. & Decision \\
\hline Corrected Model & 3.294 & 2 & 1.647 & .031 & .969 & \\
\hline Intercept & 3721.299 & 1 & 3721.299 & 70.954 & .000 & \\
\hline Pretest & .436 & 1 & .436 & .008 & .928 & \\
\hline Gender & $\mathbf{1 . 9 9 7}$ & $\mathbf{1}$ & $\mathbf{1 . 9 9 7}$ & $\mathbf{. 0 3 8}$ & $\mathbf{. 8 4 6}$ & NS \\
\hline & & & & & & \\
\hline Error & 2989.439 & 57 & 52.446 & & & \\
\hline Total & 182956.000 & 60 & & & & \\
\hline Corrected Total & 2992.733 & 59 & & & & \\
\hline
\end{tabular}

Not Significant $(\mathrm{p}>0.05)$

Table 8 shows that $\mathrm{F}$ value (.038) has a probability value of .846. Since P-value .846 was greater than 0.05 level of significance, the null hypothesis $\mathrm{H} 04$ was retained. Therefore, there was no significant difference in the mean achievement scores of male and female pupils taught English language spelling using alphabet A-J with CAI drill and practice. This shows that CAI drill and practice was not gender biased in teaching English language spelling using alphabet A-J. This is further confirmed by the result on table 8 which indicated that treatment using CAI packages produced no significant difference on gender. This result agrees with [20] who stated that computer in gender friendly. The study also revealed that, there was no significant difference in achievement in terms of gender.

Research Question 5: What are the mean retention scores of male and female pupils taught English language spelling using alphabet A-J with CAI tutorial package?

Table 9: Mean Retention Scores of Male and Female Pupils taught English Language Spelling using alphabet A-J with CAI Tutorial Package.

\begin{tabular}{|l|l|l|l|l|l|l|}
\hline & \multicolumn{2}{|l|}{ Posttest } & \multicolumn{2}{l|}{ Retention } & \\
\hline $\begin{array}{l}\text { Expt. 1 (CAI Tutorial Package) } \\
\text { Gender }\end{array}$ & N & Mean & SD & Mean & SD & $\begin{array}{l}\text { Mean } \\
\text { Gain }\end{array}$ \\
\hline Male & 25 & 57.04 & 3.88 & 57.28 & 3.31 & $\mathbf{0 . 2 4}$ \\
\hline Female & 35 & 58.17 & 2.63 & 58.17 & 4.56 & $\mathbf{0 . 0 0}$ \\
\hline Total & 60 & 57.70 & 3.23 & 57.80 & 4.08 & $\mathbf{0 . 1 0}$ \\
\hline
\end{tabular}

Table 9 shows the mean retention scores of male and female pupils taught English language spelling using alphabet A-J with CAI tutorial package. Male mean score 57.28, SD 3.31 and Female mean score 58.17 SD 4.56 with mean gains of 0.24 for males and 0.00 for females. This implies that both male and female pupils have the same retention level when taught English language spelling using alphabet A-J with CAI tutorial package.

HO $_{5}$ : There is no significant difference in the mean retention scores of male and female pupils taught English language spelling using alphabet A-J with CAI tutorial package.

Table 10: Summary of ANCOVA for Retention Scores of Male and Female Pupils taught English Language Spelling using alphabet A-J with CAI Tutorial Package.

\begin{tabular}{|l|l|l|l|l|l|l|}
\hline Source & $\begin{array}{l}\text { Type III Sum of } \\
\text { Squares }\end{array}$ & Df & Mean Square & F & Sig. & Decision \\
\hline Corrected Model & 88.705 & 2 & 44.352 & 2.831 & .067 & \\
\hline Intercept & 203.719 & 1 & 203.719 & 13.005 & .001 & \\
\hline Posttest & 77.116 & 1 & 77.116 & 4.923 & .031 & \\
\hline Gender & $\mathbf{1 . 7 4 4}$ & $\mathbf{1}$ & $\mathbf{1 . 7 4 4}$ & $\mathbf{. 1 1 1}$ & $\mathbf{. 7 4 0}$ & NS \\
\hline
\end{tabular}




\begin{tabular}{|l|l|l|l|l|l|l|}
\hline Error & 892.895 & 57 & 15.665 & & & \\
\hline Total & 201432.000 & 60 & & & & \\
\hline Corrected Total & 981.600 & 59 & & & & \\
\hline
\end{tabular}

Not Significant ( $\mathrm{p}>0.05)$

Table 10 shows that there was no significant difference in the mean retention scores of male and female pupils taught English language spelling using alphabet A-J with CAI tutorial package since the $\mathrm{F}$ value (.111) at probability level of .740 which is greater than 0.05 . This suggests therefore that CAI tutorial package is not gender sensitive in enhancing retention in English language spelling using alphabet A-J. The findings of [17] in their use of CAI for teaching English grammar revealed that there was significant difference in retention in favour of male students. This result is in disagreement with the findings of [21] whose study shows that there was no significant difference in the mean retention of male and female students. This suggests why gender in academic had remained an issue of discussion and inconclusive among scholars.

Research Question 6: What are the mean retention scores of male and female pupils taught English language spelling using alphabet A-J with CAI drill and practice?

Table 11: Mean Retention Scores of Male and Female Pupils taught English Language Spelling using alphabet A-J with CAI Drill and Practice.

\begin{tabular}{|c|c|c|c|c|c|c|}
\hline \multirow[b]{2}{*}{$\begin{array}{l}\text { Expt. } 2 \text { (CAI Drill and Practice) } \\
\text { Gender }\end{array}$} & \multirow[b]{2}{*}{$\mathbf{N}$} & \multicolumn{2}{|c|}{ Posttest } & \multicolumn{2}{|c|}{ Retention } & \multirow{2}{*}{$\begin{array}{l}\text { Mean } \\
\text { Gain }\end{array}$} \\
\hline & & Mean & SD & Mean & SD & \\
\hline Male & 28 & 55.00 & 7.92 & 54.71 & 4.63 & -0.29 \\
\hline Female & 32 & 54.56 & 6.47 & 55.13 & 6.09 & 0.57 \\
\hline Total & 60 & 54.77 & 7.12 & 54.93 & 5.42 & 0.14 \\
\hline
\end{tabular}

Table 11 shows the mean retention scores of male and female pupils taught English language spelling using alphabet A-J with CAI drill and practice. Male mean score 54.71, SD 4.63 and Female mean score 55.13, SD 6.09 with mean gains of -0.29 for males and 0.57 for females respectively. This implies that female pupils have higher retention level when taught English language spelling using alphabet A-J with CAI drill and practice than their male counterpart.

HO 6: There is no significant difference in the mean retention scores of male and female pupils

taught English language spelling using alphabet A-J with CAI drill and practice.

Table 12: Summary of ANCOVA for Retention Scores of Male and Female Pupils taught English Language Spelling using alphabet A-J with CAI Drill and Practice.

\begin{tabular}{|l|l|l|l|l|l|l|}
\hline & $\begin{array}{l}\text { Type III Sum of } \\
\text { Squares }\end{array}$ & Df & Mean Square & F & Sig. & Decision \\
\hline Corrected Model & 42.936 & 2 & 21.468 & .725 & .489 & \\
\hline Intercept & 2532.938 & 1 & 2532.938 & 85.491 & .000 & \\
\hline Posttest & 40.417 & 1 & 40.417 & 1.364 & .248 & \\
\hline Gender & $\mathbf{4 . 0 1 1}$ & $\mathbf{1}$ & $\mathbf{4 . 0 1 1}$ & $\mathbf{. 1 3 5}$ &. $\mathbf{7 1 4}$ & NS \\
\hline Error & 1688.797 & 57 & 29.628 & & & \\
\hline Total & 182792.000 & 60 & & & & \\
\hline Corrected Total & 1731.733 & 59 & & & & \\
\hline
\end{tabular}

Not Significant ( $\mathrm{p}>0.05)$

Table 12 shows that there was no significant difference in the mean retention scores of male and female pupils taught English language spelling using alphabet A-J with CAI drill

and practice since the $F$ value (.135) is significant at probability level of .714 which is greater than 0.05 . This 


\section{Effects of Two Modes of Computer Assisted Instruction on Pupils' Achievement and Retention in English Language Spelling in Niger State-Nigeria}

suggests therefore that CAI drill and practice is not gender sensitive in enhancing retention in English language spelling using alphabet A-J. In line with the above findings, [22] study on use of computer in teaching and learning oral English language revealed no significant

effect on gender retention. This result is in support of [20] whose findings show that computer is gender friendly. This shows that CAI drill and practice is not gender biased in teaching English language spelling using alphabet A-J.

\section{SUMMARY OF FINDINGS}

The major findings of this work are summarized based on the results of the analysis of data presented.

1.The pupils taught using CAI Tutorial, CAI Drill and practice achieved higher than those taught using lecture method.

2.CAI Tutorial package enhanced pupils' performance better in English Language Spelling than CAI Drill and practice package.

3.There was no significant difference in the mean achievement scores of male and female pupils taught English Spelling using CAI Tutorial, CAI Drill and practice package.

4.Female pupils had a slightly higher mean retention level than male in English Language Spelling using CAI tutorial, CAI drill and practice package.

\section{CONCLUSION}

The following conclusions were made based on the findings of this study. The result of this study provides empirical evidence that the use of CAI tutorial, CAI drill and practice packages enhanced pupils' achievement and retention in English language spelling more than the use of lecture method. Secondly, pupils' taught English language spelling with the use of CAI packages (experimental groups) performed better than their counterpart taught the same English Language spelling using lecture method. Female pupils' performed slightly higher than male pupils' using CAI tutorial and CAI drill and practice packages. There was no significant difference in gender achievement and retention of pupils taught English Language spelling with CAI packages. This implies that gender has no significant effect on achievement and retention of pupils' in English language spelling using CAI tutorial and CAI drill and practice packages. Therefore, the use of CAI packages enhanced the teaching and learning of English language spelling.

\section{RECOMMENDATIONS}

The following recommendations were made based on the findings of this study.
1. Since the use of CAI packages enhances achievement and retention of pupils' in English language spelling, the English language primary school teachers should use it as one of the strategies to be employed in classroom teaching and learning.

2. Workshops / Seminars should be organized by the Government for primary schools English language teachers to enable them learn how to develop software packages and also learn how to use computer in teaching English language especially spelling and other topics in English language.

3. Primary school teachers should be encouraged to be computer literate. This will enable them to appreciate and use CAI packages to promote effective teaching and learning among others.

\section{REFERENCES}

[1] Federal Ministry of Education, National Policy on Education - 4th edition. NERDC Press Lagos: 2009.

[2] D. C. U. Okoro, Basic education- emerging issues, challenges and constraints in the state of education in Nigeria. A Publication of UNESCO Nigeria, Abuja Office. [2002] pp 34-51.

[3] C. O. O. Kolawole, An examination of national language policy Nigeria and its' implications for teaching and learning of English language. Ibadan Journal of Education Studies. 2(1), [2002], pp12-20.

[4] U. Y. Adama, Availability and utilization of instructional materials in the teaching and learning of English language in senior secondary schools in Bida, Niger State. An Unpulished M.Tech project, Federal University of Technology, Minna. [2009].

[5] A. A. Onwumere, The integration and use of computer assisted instruction (CAI) to enhance understanding in learning and competency in use of English language in primary schools in Nigeria. Proceedings of the 33RD Annual Convention and International Conference on Instructional Delivery Through ICT, Nigeria Association for Educational Media and Technology held on 8th-12th October, [2012]. College of Education Oyo, Oyo State. pp 45-55.

[6] NTI, National Teachers' Institute Kaduna. Manual for the re-training of English language primary school teachers. [2006] pp 23.

[7] Tompkins, Teaching spelling. Retrieved online 16/12/13, http://www. slideshare.net/itsdanimoe/teachingspelling. [2012].

[8] Wallace, Teaching spelling. Retrieved online 16/12/13 http://www. slideshare.net/itsdanimoe/teaching-spelling. [2006]. 
[9] P. Westwood, Writing skills in the classroom: handwriting and spelling, Literacy: Reading, writing and children literature. Australia: oxford university press. [2002] pp 217-243.

[10] P. Wood, The effect of text messaging on 9-10 years old children's writing, spelling and phonological processing skills. Covently, U.K. Psychology Department Covaltry University. [2010] pp 61.

[11] Vamhagen, New spelling and writing in instant messaging. Published on line: 2nd may. [2009] pp 61.

[12] Wikipedia, Tutorial. Retrieved on 16/12/13 from: http://en. Wikipedia. Org/wiki/tutorial, the free encyclopedia. [2013].

[13] Q. J. Nwoji, Production and utilization of teaching materials. Nsukka: Fulladu publishers. [2002].

[14] Wekipedia, Web. Retrieved 1/6/2020. https://www.definition. Net definition/academic + achievement. [2020].

[15] D. I. Wushishi, K. I. Danjuma, \& H. Usman, Effect of concept mapping modes on sec school students' retention level in mathematics in Niger State, Nigeria. Journal of Research and Method in Education, (IOSE- JRME). [2013]. 2 (5) pp 55-58.

[16] A. Yusuf, Effects of cooperative and competitive instructional strategies on junior secondary school students' performance in social studies, in Ilorin, Nigeria. Unpublished Ph.D Thesis, Curriculum Studies and Educational Technology, University of Ilorin, Nigeria. [2004].

[17] A. Abdullah, H. Jebreen, A. Aieman, \& S. Sadeq, The effect of computer assisted language learning in teaching English grammar on achievement of students in Jordan. The International Arab Journal of Information technology. [2009] 6(4), pp 431-439.

[18] R. C. Mishra, Teaching of information technology. New Delhi: APH Publishing Corporation. [2007].

[19] A. Alongkorn, N. Wiphasith, P. Nipon, \& S. Tonglan, Developing a computer assisted instruction with drill and practice for English teaching to primary school grade six students with hearing impaired. Journal of the Computer, the Internet and Management. [2014]22, pp47-53.

[20] M. I. Chado, Development and use of a computerassisted instruction package for teaching metal forging technology at Nigerian Certificate of Education (Technical) Level. Unpublished Ph.D Thesis Bauchi: Abukar Tafawa Barewa University. [2009].

[21] A. F. Naobi, Enhancing students' performance in using computer assisted instruction (CAI) in tertiary institution. In Akale, Mag (Ed).Proceedings of the 44th Annual
Conference of Science teachers Association of Nigeria (STAN). [2003].

[22] G. K. Ezekoka, Effect of gender on use of computer in teaching and learning process. Proceedings from 31st Annual Convention and National Conference of Nigeria Association of Educational Media and Technology (NAEMT) held at Niger State College Education, Minna 20th -26th September. [2010].

\section{ABOUT THE AUTHORS}

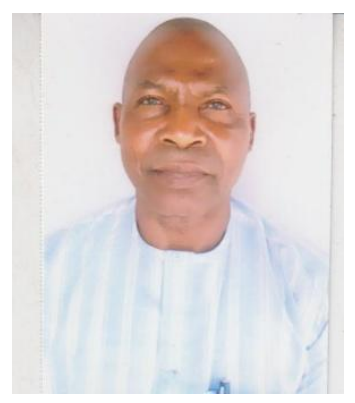

Aniah Anthony had his Ph.D from University of Nigeria Nsukka, Enugu State, Nigeria. He is a senior lecturer in the Department of Educational Technology, Federal University of Technology, Minna Niger State, Nigeria. He instruct undergraduate, masters and Ph.D students. He has supervised more than fifty undergraduate students' projects including masters and $\mathrm{Ph} . \mathrm{D}$ thesis and had published more than forty works to his credit. $\mathrm{He}$ is a member of Educational Media and Technology Association of Nigeria (EMTAN). He is also a member of International Vocational Education and Training Association (IVETA). His hobbies are adventure and long distance trekking to keep the body system in good shape. Email: anthonyaniah@futminna.edu.ng, Phone No. 08036195385

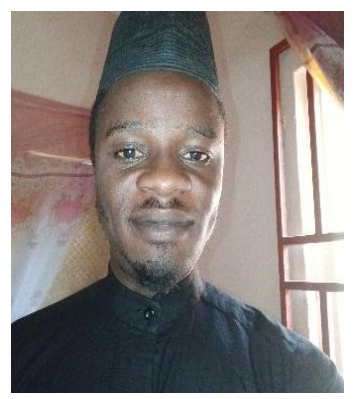

Sani Shahid Anka is a principal instructor 1 with the Department of Office Technology and Management, Abdu Gusau Polytechnic, Talata Mafara, Zamfara State, Nigeria. He holds a Higher National Diploma in Secretarial Administration from Abdu Gusau Polytechnic, Talata Mafara, Zamfara State, M. Ed Educational Technology from National Open University Nigeria. $\mathrm{He}$ is presently pursing a Ph.D degree in view, in Educational Technology, Department of Educational Technology, Federal University of Technology, Minna, Niger State, Nigeria.Email: shaheedsani@gmail.com. Phone No.08064893471 